\section{Comparison of two assessment instruments of quality of life in older adults}

\section{Comparação de dois instrumentos de avaliação de qualidade de vida emidosos}

\section{Camila Mello dos Santos'}

Fernando Neves Hugo, ${ }^{1,1}$

Andréa Fachel Leal"'

\section{Juliana Balbinot Hilgert'}

'Department of Preventive and Social Dentistry, Faculty of Dentistry, Federal University of Rio Grande do Sul, Porto Alegre, Brazil.

"Community Dental Health Research Center, Federal University of Rio Grande do Sul, Porto Alegre, Brazil.

"'Department of Sociology, Philosophy and Humanities Institute, Federal University of Rio Grande do Sul, Porto Alegre, Brazil.

\section{Abstract}

Objective: To investigate if there is convergent validity between the dimensions of the World Health Organization Quality of Life Questionnaire-Brief Version (WHOQOLBref) and the Oral Health Impact Profile-14 (OHIP-14) questionnaire. Methods: In this cross-sectional study, a random sample of 872 elderly Southern-Brazilians was evaluated. Questionnaires assessing sociodemographic data and quality of life in general (WHOQOL-Bref) and oral healthrelated quality of life (OHIP-14) were used. Analysis of the WHOQOL-Bref and OHIP-14 questionnaires used descriptive statistics. The dimensions of the WHOQOL-Bref and OHIP-14 questionnaires were correlated by affinity. The convergence between WHOQOL-Bref and OHIP-14 dimensions was analyzed by Spearman's correlation coefficients. Results: The social relations dimension of the WHOQOL-Bref presented the greatest mean $(18.24 \pm 2.30)$. The physical pain dimension of the OHIP-14 presented a median of $1.0(0.0-3.0)$. All correlations between the WHOQOL-Bref and OHIP-14 dimensions were significant, negative and associated with a low magnitude. The correlation between WHOQOL-physical and OHIP-functional limitation, OHIP-physical pain, OHIP-physical disability and OHIPhandicap were $-0.164,-0.262,-0.196$ and 0.125 respectively. WHOQOL-psychological was associated with OHIP-psychological discomfort and OHIP-psychological disability, and WHOQOL-social showed an association with OHIP-social disability. Conclusions: All correlations analyzed had a positive association of low magnitude. Despite the fact that theWHOQOL-Bref and OHIP-14 instruments have related dimensions, they measure physical, psychological and social relations differently.

Keywords: Quality of life. Aging. Questionnaires. Oralhealth. OHIP,WHOQOL-Bref. 


\section{Resumo}

Objetivo: Investigar se existe convergência entre as dimensões da versão abreviada do questionário da Organização Mundial da Saúde sobre Qualidade de vida (WHOQOLBref) e do questionário Perfil do Impacto de Saúde Bucal-14 (OHIP-14). Métodos: Neste estudo transversal, uma amostra randomizada de 872 idosos do sul do Brasil foram avaliados. Questionários sobre informações de dados sociodemográficos e de qualidade de vida em geral (WHOQOLBref) e de qualidade de vida relacionada à saúde bucal (OHIP-14) foram utilizados. Foi utilizada estatística descritiva para analisar os questionários WHOQOL-Bref e OHIP-14. As dimensões dos questionários WHOQOL-Bref e OHIP-14 foram correlacionas por afinidade. A convergência entre as dimensões doWHOQOL-Bref e do OHIP-14 foi analisada pelos coeficientes de correlação de Spearman. Resultados: A dimensão relação social do WHOQOL-Bref foi a que apresentou maior média $(18.24 \pm 2.30)$. A dimensão dor física do OHIP-14 apresentou mediana $1.0(0.0-3.0)$. Todas as correlações entre as dimensões do WHOQOL-Bref e do OHIP-14 foram significativas, negativas e com associação de baixa magnitude. As correlações entre WHOQOL- físico e OHIP- limitação funcional, OHIP-dor física, OHIP-limitação física e OHIP-desvantagem foram $-0,164,-0,262,-0,196 \mathrm{e}-0,125$, respectivamente. WHOQOL-psicológico foi associado com OHIP-disconforto psicológico e OHIP-limitação psicológica, e WHOQOL-social mostrou associação com OHIP-limitação social. Conclusões: Todas as correlações analisadas apresentaram associação positiva de baixa magnitude. Apesar dos questionários WHOQOL-Bref and OHIP-14 apresentarem dimensões relacionadas, eles medem as relações físicas, sociais e psicológicas de maneira diferente.

Palavras-chave: Qualidade de vida. Envelhecimento. Questionários. Saúde bucal. OHIP. WHOQOL-Bref.

\section{Introduction}

The world life expectancy increase has demanded actions in order to assess and improve health and the quality of life of elderly people ${ }^{1}$. According to The World Health Organization Quality of Life Group (WHOQOL) $)^{2}$, "Quality of life is the perception of an individual about his position in life, according to the cultural context and system of values in which he lives as well as in relation to his objectives, expectations, patterns and concerns". The term quality of life, when related to health, involves aspects more directly associated to diseases or health interventions ${ }^{3}$. The concept of quality of life is wider and more subjective than the definitions above, considering that good mental and physical health influences good quality of life of older persons ${ }^{4}$.

Oral health is part of health as a whole and it is an important factor for quality of life $^{5}$. Oral health-related quality of life has been defined as "the absence of negative impacts of oral conditions on social life and a positive sense of dentofacial self-confi-

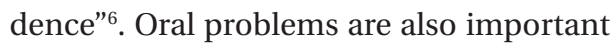
for oral health- related quality of life because such problems are experienced in daily life, bringing functional, social and psychological impacts ${ }^{7}$. According to Brondani et al. $(2008)^{8}$, little is known about the complexity of personal factors that affect the perception of oral health. The negative impact of oral conditions for older person's quality of life is a public health problem, which has to be contemplated by public health policies ${ }^{9}$.

There are some instruments that assess the individual's perception on subjective aspects of his/her own health and these indicators may be used to better assess his/her health conditions ${ }^{10}$. The literature has provided different instruments for measuring quality of life ${ }^{11}$, including the World Health Organization Quality of Life QuestionnaireBrief Version (WHOQOL-Bref) $)^{12-14}$ and the Oral Health Impact Profile-14 (OHIP-14) ${ }^{15-}$

${ }^{16}$, both considered valid constructs. The WHOQOL-Bref is a questionnaire that assesses how an individual feels about his 
quality of life, health and other areas of his life in the previous two weeks. The OHIP-14 provides a broad measurement of dysfunction, discomfort and disability attributed to oral condition in the previous months.

The WHOQOL-Bref assesses the quality of life in general and the OHIP-14 assesses the impact of oral conditions on quality of life, and there is little research that correlates these two instruments in older people. Both constructs encompass, in general, the perception of health and its impact on social, psychological and physical dimensions ${ }^{17}$. However, the different dimensions of the WHOQOL-bref may not be automatically transferred to several dimensions of the OHIP-14. Nevertheless, in these two constructs there are some dimensions that intend to describe the same aspects of quality of life.

Convergent and discriminant validity are considered subcategories or subtypes of construct validity ${ }^{18}$. Measures of constructs that theoretically should be related to each other are, in fact, observed to be related to each other (that is, one should be able to show a correspondence or convergence between similar constructs). Measures of constructs that theoretically should not be related to each other are, in fact, observed to not be related to each other (that is, one should be able to discriminate between dissimilar constructs) ${ }^{19-20}$.

The measurements of quality of life have several applications: population studies on the perception of health conditions, measurements of the results in healthcare services, clinical trials and economical analyses that focus on the monetary cost needed for assuring better quality of life ${ }^{19}$. In relation to the instruments of quality of life, the use of simultaneously generic and specific measurements may demonstrate broader results than when applied individually $^{21}$. According to the literature, there are no studies comparing the dimensions of WHOQOL-Bref and OHIP-14. The hypothesis of the present study is that these dimensions are convergent. The objective was to investigate if there is convergent validity between the dimensions of WHOQOL-Bref and OHIP-14 questionnaires.

\section{Methods}

\section{Sample}

The present study was based on data collected with both questionnaires WHOQOLBref and OHIP-14, in a larger study carried out during 2004, about the effects of oral diseases on general health and quality of life of older people living in the city of Carlos Barbosa, Rio Grande do Sul, Brazil22 . Participants were randomly selected from the city register of persons aged 60 years or more. After contacting 983 older persons, 872 accepted to take part in the present study and were subsequently evaluated. Further details regarding sampling are shown in a previously published paper ${ }^{23}$. This study was carried out after approval by the Ethics Committee of the Faculty of Dentistry of Piracicaba, UNICAMP (protocol 055/2004) and all participants provided written consents.

\section{Study measures}

Data collection comprised of face-to-face interviews was conducted in the participant's homes or community clubhouses. Participants were informed about the study objectives and were asked to sign informed consent forms. A research assistant trained by an experienced researcher read all questions aloud and registered participants answered them in a standardized questionnaire. The average duration of the interview was one hour.

Socio-demographic data included information regarding age, sex, marital status (not married or married), schooling ( $<4$ years, 4 years or $>4$ years of formal education), monthly income $(=<1$ minimum wage or $>$ 1 minimum wage, one Brazilian minimum wage was equivalent to U\$219.50, during the data collection period) and geographic location of participants' residence (rural or urban). 
The WHOQOL-Bref contains 26 questions evaluating four different domains of quality of life: physical (seven questions), psychological (six questions), social relations (three questions), and environmental (eight questions). In the physical domain, participants answered questions such as 'To what extent do you feel that physical pain prevents you from doing what you need to do?' or 'Do you have enough energy for everyday life?'. In the psychological domain, participants answered questions such as 'How much do you enjoy life?' or 'Are you able to accept your bodily appearance?'. In the social relations domain, participants answered questions such as: 'How satisfied are you with your personal relationships?'. The response scales used assessed 'how much', 'how completely', 'how often', 'how good' or 'how satisfied' the older persons felt in the previous two weeks. Responses varied according to a five-point Likert interval scale. The score range for each WHOQOLBref item is $1-5$, whilst the score range for each WHOQOL-Bref dimension is $4-20$. The lower scores imply poorer quality of life. The present study used the validated Brazilian Portuguese version of the WHOQOL-Bref.

The OHIP-14 is composed of fourteen questions, two for each of the seven dimensions of the instrument. In the functional limitation dimension, participants responded to questions such as 'Have you had trouble pronouncing any words because of problems with your teeth, mouth or dentures?'. In the physical pain dimension, they were asked questions such as 'Have you had painful aching in your mouth?'. Questions in the psychological discomfort dimension were also asked, such as 'Have you been self-conscious because of your teeth, mouth or dentures?'. In the physical disability dimension, participants were asked the following: 'Have you had to interrupt meals because of problems with your teeth, mouth or dentures?'. In the psychological disability dimension, questions were as follows: 'Have you been a bit embarrassed because of problems with your teeth, mouth or dentures?'. There were also questions in the social disability dimension, such as 'Have you had difficulty doing your usual jobs because of problems with your teeth, mouth or dentures?'. Additionally, in the handicap dimension, they were asked questions such as 'Have you felt that life in general was less satisfying because of problems with your teeth, mouth or denture?'. The responses were classified through the Likert scale with five options ranging from 'never' (0) to 'very often' (4). Lower scores imply better oral health-related quality of life. The present study used the validated Brazilian Portuguese version of the OHIP-14.

\section{Procedures for data analysis}

\section{First Analysis}

Socio-demographic data were analyzed through descriptive statistics, including mean, standard deviation, and relative frequency. Analysis of the WHOQOL-Bref and OHIP-14 questionnaires also used the same descriptive statistics, but included the median and the quartiles.

\section{Second Analysis}

In the present work, the dimensions of OHIP-14 andWHOQOL-Bref questionnaires were correlated by affinity. The physical dimension of theWHOQOL-Bref questionnaire, contemplating questions related to pain, discomfort, energy, fatigue, and capacity for working, was correlated with functional limitation, physical pain, physical disability, and handicap of the OHIP-14 questionnaire, which assesses questions related to painful aching, discomfort eating and inability to function. The psychological dimension of the WHOQOL-Bref contains questions about feelings, appearance and self-esteem, and it was correlated with the psychological discomfort and psychological disability dimensions of the OHIP-14 that assesses questions on tensing and embarrassment of the oral condition. The social dimension of the WHOQOL-Bref evaluates questions about social support and personal relations. This dimension was correlated with the social disability of the OHIP-14, which 
assesses questions related to irritability with others and difficulty to perform usual jobs because of oral problems. The environmental dimension of the WHOQOL-Bref involves leisure questions, transportation and financial resources; this last dimension was not correlated with OHIP-14 dimensions, as it did not present a similar aspect in the assessment of quality of life. The scheme of hypothesized correlations has been shown in Figure 1.

\section{Third Analysis}

WHOQOL-Bref and OHIP-14 reliabilities were tested with Cronbach's Alpha Coefficient. Rowland et al. (1991) ${ }^{24}$ recommended the minimum value of 0.70 , by considering that items assess the same construct consistently. Similar constructs should reveal a correspondence or convergence between them, whilst dissimilar constructs should allow for discrimination between them ${ }^{19}$. The convergence between WHOQOL-Bref and OHIP-14 dimensions was analyzed by Spearman's correlation coefficients. Correlations between theoretically similar measures should be high, while correlations between theoretically dissimilar measures should be low. According to Huang et al. $(2006)^{25}$, similar constructs were moderately to strongly correlated $(\mathrm{r} \geq$ 0.40 ), while dimensions measuring heterogeneous constructs were weakly correlated $(r<0.40)$. In this study, the value of $r \geq 0.40$ was used as a cutoff point for convergence and $\mathrm{r}<0.40$ for divergence between constructs. Thus, the correlations between the dimensions ofWHOQOL-Bref and OHIP-14 questionnaires are expected to be negative, as the measuring scales are opposite. A negative correlation can be interpreted as a positive association, because an increase in the WHOQOL-Bref score implies better quality of life, as do lower scores of OHIP-14.

All analyses were performed using the SPSS 12.0 (SPSS Inc., Chicago, IL, USA) software for statistical analysis.

\section{Results}

In relation to the socio-demographic data of the studied sample, there was a greater participation of women $(64.6 \%)$; the mean age was of $68.5( \pm 6.7)$ years and they were residents of the rural zone $(52.1 \%)$. The majority of participants were married

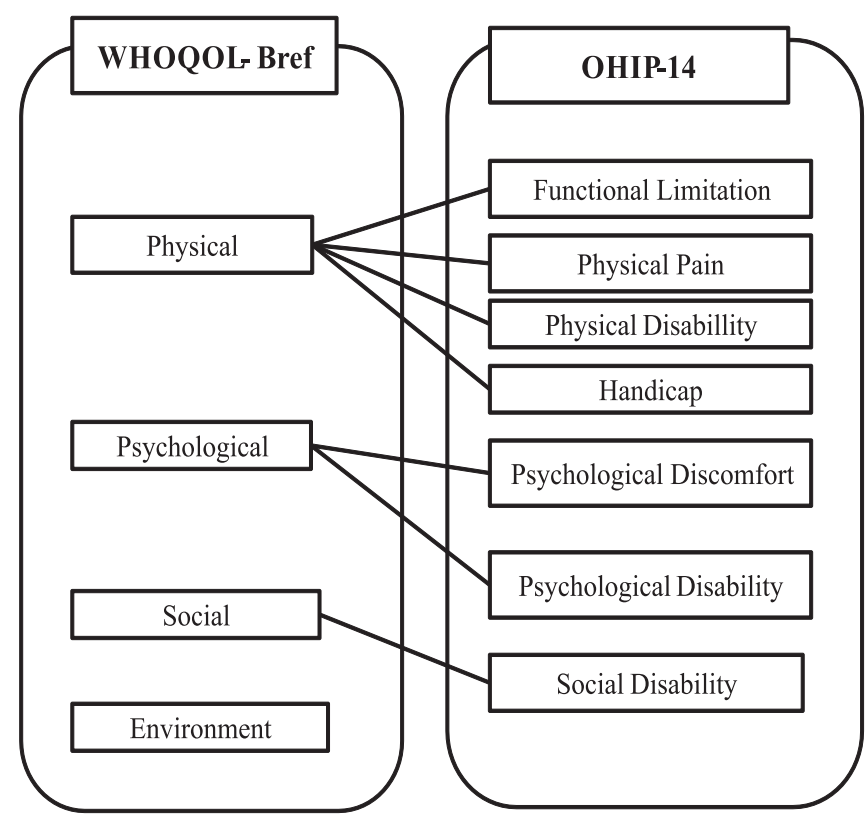

Figure 1 - Correlations between the WHOQOL-Bref and OHIP-14.

Figura 1 - Correlações entre o WHOQOL-Bref e o OHIP-14. 
(71.6\%). Participants had four years of formal education (40.8\%) and an income of up to one minimum wage $(58.1 \%)$.

The means for all four domains of the WHOQOL-Bref and for all seven dimensions of the OHIP-14 are presented in Table 1 . The domain with the highest mean in the WHOQOL-Bref was the social domain (18.24 \pm 2.30$)$, with a median of 20.00 (16.00 -20.00 ). The physical pain dimension in the OHIP-14 presented the highest mean (1.76 $\pm 2.03)$, with a median of $1.00(0.00-3.00)$.

Cronbach's Alpha Coefficient for the WHOQOL-Bref questionnaire was 0.80 , while that for the OHIP-14 was 0.86 .

The correlation between dimensions of both questionnaires is presented in Table 2 . All correlations analyzed were significant, negative and had a low magnitude. The greatest negative correlation was found in the WHOQOL-Bref psychological domain and the OHIP-14 psychological discomfort dimension.

\section{Discussion}

To our knowledge, this is the first study that correlates dimensions of the WHOQOL-Bref and OHIP-14 questionnaires. Dimensions of both questionnaires that are conceptually similar have been associated, but these questionnaires measure different aspects of quality of life related to health. Thus, a negative correlation can be interpreted as a positive association, because the WHOQOL-Bref and OHIP-14

Table 1 - Score distributions of the WHOQOL-Bref and OHIP-14 $(n=872)$.

Tabela 1 - Escores da distribuição do WHOQOL-Brefe do OHIP-14 $(n=872)$.

\begin{tabular}{lccc}
\hline Questionnaire-Dimension & Number of items & Mean \pm SD & Median $(\mathrm{p} 25-\mathrm{p} 75)$ \\
\hline OHIP- Functional Limitation & 2 & $0.84 \pm 1.53$ & $0.0(0.0-1.0)$ \\
OHIP- Physical Pain & 2 & $1.76 \pm 2.06$ & $1.0(0.0-3.0)$ \\
OHIP- Psychological Discomfort & 2 & $1.12 \pm 2.02$ & $0.0(0.0-2.0)$ \\
OHIP- Physical Disability & 2 & $0.85 \pm 1.51$ & $0.0(0.0-1.0)$ \\
OHIP- Psychological Disability & 2 & $0.49 \pm 1.24$ & $0.0(0.0-0.0)$ \\
OHIP-Social Disability & 2 & $0.17 \pm 0.68$ & $0.0(0.0-0.0)$ \\
OHIP-Handicap & 2 & $0.32 \pm 0.96$ & $0.0(0.0-0.0)$ \\
WHOQOL- Physical & 7 & $14.79 \pm 2.24$ & $14.85(13.14-16.57)$ \\
WHOQOL-Psychological & 6 & $15.94 \pm 1.82$ & $16.66(14.66-17.33)$ \\
WHOQOL-Social & 3 & $18.24 \pm 2.30$ & $20.00(16.00-20.00)$ \\
WHOQOL-Environment & 8 & $15.95 \pm 2.11$ & $16.00(14.50-17.50)$ \\
\hline
\end{tabular}

Table 2 - Correlation coefficients between the WHOQOL-Bref and OHIP-14 $(n=872)$.

Tabela 2 - Coeficientes das correlações entre o WHOQOL-Bref e o OHIP-14 $(n=872)$.

\begin{tabular}{lccc}
\hline & WHOQOL- Physical & WHOQOL- Psychological & WHOQOL- Social \\
\hline OHIP- Functional Limitation & $-0.164^{*}$ & - & - \\
OHIP- Physical Pain & $-0.262^{*}$ & - & - \\
OHIP- Psychological Discomfort & - & $-0.269^{*}$ & - \\
OHIP- Physical Disability & $-0.196^{*}$ & - & - \\
OHIP- Psychological Disability & - & $-0.210^{*}$ & - \\
OHIP- Social Disability & - & - & $-0.217^{*}$ \\
OHIP- Handicap & $-0.125^{*}$ & - & - \\
\hline
\end{tabular}

Note: All* $\mathrm{p}$ value $<0.0001 . /$ Nota: Todos valores $p<0,0001$. 
questionnaires measure scales that are opposite. The correlations between dimensions of both questionnaires had a low magnitude. Despite the fact that both instruments have related dimensions, they measure physical, psychological and social relations differently.

In this study, the low correlations found between the dimensions of the WHOQOLBref and OHIP-14 questionnaires may be explained by the fact that theoretically different constructs must not be closely associated among themselves. It should be noted that the quality of life related to oral health is conceptually different from quality of life in general ${ }^{3}$, and that the instruments of quality of life related to oral health have been focused on negative experiences and functional inability caused by oral proble$\mathrm{ms}^{26}$. The WHOQOL-Bref is a generic instrument of quality of life, that is, it is not aimed at assessing dimensions normally affected by a specific health problem. However, the OHIP-14, which is a specific indicator, was developed with the purpose of identifying impacts related to oral conditions.

Quality of life is a multidimensional concept related to the fact that life involves multiple dimensions: material, physical, social, and psychological, among others ${ }^{13}$. Quality of life related to health includes aspects related to health, but excludes other aspects that are more general and broader, which are contemplated in the expanded approach of quality of life, such as the environmental dimension ${ }^{14}$. Studies on oral health and quality of life derive from the approach to four dimensions: pain and discomfort, functional aspects, psychological aspects and social aspects? ${ }^{7}$.

The WHOQOL was created based on the assumption that quality of life is a subjective construction (individual perception), it is multidimensional (involves cultural, social and environmental aspects), and it encompasses not only positive aspects but also negative ones ${ }^{14}$. The multidimensional nature of the construct was validated from the emergence of four great dimensions or factors: (a) physical-individual's perception on his physical condition; (b) psychological -individual's perception on his affective and cognitive condition; (c) social - individual's perception on his social relationships and his social roles adopted in life; (d) environmental - individual's perception on several aspects related to the environment where he lives ${ }^{13}$.

The OHIP was developed from the necessity of determining the real impact of oral problems on the individuals' lives, that is, in order to provide a broader measuring of the dysfunction, discomfort and disability attributed to the oral condition ${ }^{28}$. The model used for developing the conceptual dimensions of the OHIP construct was Locker's theoretical model (1988) ${ }^{29}$. In this model, disease may lead to impairment, defined as an anatomical loss or abnormality - a tooth loss, for instance. This impairment, then, may lead to a functional limitation, described as the functional loss of parts of the body or systems, such as the difficulty in hearing certain sounds. Impairment may also bring pain or discomfort, not only physical but psychological as well. One or the other may lead to psychological or social disability, described by the author as any limitation or lack of ability to perform daily routine activities ${ }^{29}$. This model is based on the classification of the World Health Organization in which the impact of diseases has been categorized in a hierarchy that ranges from an individual's apparently primary mild symptoms to incapacitation, affecting his social roles ${ }^{30}$.

According to Allen et al. (1999) ${ }^{31}$, the specific problems of instruments related to oral health allow for better measurement of quality of life aspects than the generic instruments of quality of life, such as the SF-36 (Medical Outcomes Study 36-Item Short-Form Health Survey). Allen and McMillan (2003) ${ }^{32}$ also utilized the OHIP and SF-36 instruments to measure the impact of dental treatment on the quality of life of adult individuals and found that the constructs that allow the measurement of specific aspects related to oral health are more sensitive than the instruments that 
focus on general health. In this study, the dimensions predicted as those that assess similar aspects did not correlate.

Some authors defend the use of specific instruments in quality of life studies, arguing that these may help elucidate the characteristics related to specific health issues, while other authors state that such specific instruments are restricted to symptoms and to dysfunctions, contributing little to a better understanding of quality of life aspects $^{33}$. Within a broader health model, a general quality of life instrument may be more fruitful in the perspective of creating knowledge for better health care for individuals and for the social group ${ }^{34}$.

Any study of oral health assessing quality of life in a broader sense may benefit from the use of both specific and generic instruments, once the mouth is part of a body, which is included in a social environment. The human body is not only a biological system: the body is immersed in culture, thus being affected by social and cultural facts, norms, and values, such as religion, work, family, and social class. The mouth has both biological (chewing) and social (speaking, smiling, communicating) uses, it connotes proximity and intimacy in daily social interactions, and it is a tool for communicating with society and the world ${ }^{35}$.

The results of this study must be interpreted with caution, since the WHOQOLBref and OHIP-14 evaluate what respondents think about their quality of life following different periods of time. While the WHOQOL-Bref considers the previous two weeks, the OHIP-14 considers the previous six months. One important criticism to the use of the previous two weeks in the WHOQOL-Bref is that the health status is unlikely to change substantially in such a short period of time. However, all impacts in the OHIP-14 are conceptualized as adverse outcomes, and therefore the absence of negative conditions would necessarily imply a positive status. However, it is also important to take into account that the oral health problems and impacts experienced by older persons are chronic in its nature, meaning that they are experienced for periods that are much longer than two weeks or six months.

Some limitations must be considered in the interpretation of the results of the present study. The generalization of the results may be affected by the characteristics of the sample, mainly consisted by older individuals with low income from a rural community.

\section{Conclusion}

Dimensions of the WHOQOL-Bref and OHIP-14 questionnaires that are conceptually similar were associated with each other, although these questionnaires measure different aspects of quality of life related to health. In this study, all correlations analyzed had a positive association of low magnitude. Correlations between theoretically similar measures should be high, while correlations between theoretically dissimilar measures should be low. Despite the fact that both instruments have related dimensions, they measure physical, psychological and social relations differently. Further studies involving different age groups and in different socio-cultural contexts will certainly contribute to a better understanding of assessments of quality of life, and of quality of life related to health through theWHOQOL-Bref and OHIP-14 questionnaires.

Conflict of interest: The authors declare that they have no conflicts of interest. 


\section{References}

1. World Health Organization. Healthy aging: practical pointers on keeping well. Geneve, Switzerland: World Health Organization; 2005.

2. The WHOQOL Group. The World Health Organization Quality of Life Assessment: Position paper from the World Health Organization. Soc Sci Med 1995; 10: 1403-9.

3. Seidl EMF, Zannon, CMLC. Quality of life and health: conceptual and methodological issues. Cad Saude Pública 2004; 20: 580-8.

4. Vecchia RD, Ruiz T, Bocchi SCM, Corrente JE. Qualidade de vida na terceira idade: um conceito subjetivo. Rev Bras Epidemiol 2005; 8: 246-52.

5. Tesch FC, Oliveira BH, Leão A. Measuring the impact of oral health problems on children's quality of life: conceptual and methodological issues. Cad Saude Pública 2007; 23: 2555-64.

6. Atchison KA. Understanding the Quality in Quality Care and Quality of Life. In: Inglehart MR, Bagramian RA. Oral Health-Related Quality of Life.USA: Quintessence Books; 2002: pp. 13-29.

7. Locker D. Subjective oral health status indicators. Commmunity Dent Health 1997; 27: 257-70.

8. Brondani MA, MacEntee MI, Bryant SR, O’Neill B. Using written vignettes in focus groups among older adults to discuss oral health as a sensitive topic. Qual Health Res 2008; 18: 1145-53.

9. Petersen PE, Yamamoto T. Improving the oral health of older people: the approach of the WHO Global Oral Health Programme. Community Dent Oral Epidemiol 2005; 33: 81-92.

10. Dinakel B, Locatelli FA, Fadel CB, Baldani MH. Associação entre percepção de saúde bucal e indicadores clínicos e subjetivos: estudo em adultos de um grupo de educação continuada da terceira idade. $\mathrm{Ci}$ Biol.Saúde 2003; 9: 55-65.

11. Hebling E, Pereira AC. Oral health-related quality of life: a critical appraisal of assessment tools used in elderly people. Gerodontology 2007; 24: 151-61.

12. Fleck MPA, Leal OF, Louzada S, Xavier M, Chachamovich E, Vieira $\mathrm{G}$ et al. Desenvolvimento da versão em português do instrumento de avaliação da qualidade de vida da OMS (WHOQOL-100). Revista Brasileira de Psiquiatria 1999; 21: 19-28.

13. Fleck MPA. O instrumento de avaliação de qualidade de vida da Organização Mundial da Saude (WHOQOL-100): características e perspectivas. Revista Ciencia e Saude Coletiva 2000; 5: 33-8.

14. Fleck MPA, Louzada S, Xavier M, Chachamovich E, Vieira G, Santos L et al. Application of the Portuguese version of the abbreviated instrument of quality life WHOQOL-bref. Rev Saude Pública 2000; 34: 178-83.
15. Slade GD. Derivation and validation of a short-form oral health impact profile. Community Dent Oral Epidemiol 1997; 25: 284-90.

16. Oliveira BH, Nadanovsky P. Psychometric properties of the Brazilian version of the Oral Health Impact Profileshort form. Community Dent Oral Epidemiol 2005; 33: 307-14.

17. Testa Ma, Simonson DC. Assessment of quality of life outcome. N Eng J Med 1996; 334: 835-840.

18. Westen D, Rosenthal R. Quantifying construct validity: two simple measures. J Pers Soc Psycho 2003; 84: 608-18.

19. Fitzpatrick R, Fletcher A, Gore S, Jones D, Spiegelhalter D, Cox D. Quality of life measures in health care. I: Applications and issues in assessment. BMJ 1992; 31: 1074-7.

20. Trochim WMK. Research Methods Knowledge Base, 2006. Retrieved May 10, 2010, from http://www. socialresearchmethods.net/kb/constval.php.

21. Fayers PM, Machin D. Quality of life assessemnet, analysys and interpretation. England: Jonh wiley e sons LTD; 2000.

22. Hugo FN, Hilgert JB, de Sousa MdaL, Cury JA. Oral status and its association with general quality of life in older independent-living south-Brazilians. Community Dent Oral Epidemiol 2009; 37: 231-40.

23. Hilgert JB, Hugo FN, de Sousa MdaL, Bozzetti MC. Oral status and its association with obesity in Southern Brazilian older people. Gerodontology 2009; 26: 46-52.

24. Rowland D, Arkkelin D, Crisler L. Computer-based data analysis: using SPSSx in the social and Behavioral Sciences. Chicago: Nelson-Hall; 1991.

25. Huang IC, Wu AW, Frangakis C. Do the SF-36 and WHOQOL-BREF measure the same constructs? Evidence from the Taiwan population. Quality of Life Research 2006; 15: 15-24.

26. Brondani MA, MacEntee MI. The concept of validity in sociodental indicators and oral health-related qualityof-life measures. Community Dent Oral Epidemiol. 2007; 35: $472-8$.

27. Minayo MCS, Hartz ZMA, Buss PM. Qualidade de vida e saúde: um debate necessário. Ciência \& Saúde Coletiva 2000; 5: 7-18.

28. Slade GD, Spencer AJ. Development and evaluation of the Oral Health Impact Profile. Community Dent Health 1994; 11: 3-11.

29. Locker D. Measuring oral health: a conceptual framework. Community Dent Health 1988; 5: 5-13. 
30. WHO. World Health Organization: International classification of impairments, disabilities and handicaps: a manual of classification. Geneva, Switzerland: World Health Organization; 1980.

31. Allen PF, McMillan AS, Walshadaw D. A comparison of the validity of generic and disease specific measures in the assessment of oral health-related quality of life. Community Dent Oral Epidemiol 1999; 27: 344-52.

32. Allen PF, McMillan AS. A longitudinal study of quality of life outcomes in older adults requesting implant prostheses and complete removable dentures. Clin Oral Impl Res 2003; 14: 173-9.
33. Gladis MM, Gosch EA, Dishuk NM, Crits-Christoph P. Quality of life: expanding the scope of clinical significance. J Consult Clin Psychol 1999; 67: 320-31.

34. Ebrahim S. Clinical and public health perspectives and applications of healthrelated quality of life measurement. Soc Sci Med. 1995; 41: 1383-94.

35. Rodrigues JC. O tabu do corpo. Rio de Janeiro: Achiamé; 1979.

Recebido em: 27/06/11

Versão final apresentada em: 08/11/11

Aprovado em: 16/02/12 